\section{ROYAL MEDICAL AND CHIRURGICAL} SOCIE'TY.

May 24, 1842.

Dr. Willians, President.

Cases of Malformation of the Heart. By BELL Fletcher, M.D., Physician to the General Dispensary, Birmingham.

The first of these was one of aneurism and dilatation of the pulmonary artery, malformation of the heart and arteries. The patient was a young woman, aged nineteen, who, with the exception of slight cough, had enjoyed good health up to the age of sixteen; since that time she has had frequent attacks of pain in the chest, cough, and dyspnca. She was first seen by the author in August, 1839, when she had cough and dyspnœa, with slight hæmoptysis. On the left side of the sternum, between the sccond and third ribs, there was a superficial pulsation, with purring tremor, and a loud rasping souftle; the impulse of the heart was normal. She recovered under the use of the remedies employed, but had several similar attacks between that time and December, 1840 , when she had severe inflammation of the lungs. At this time the pulsation of the ahest mentioned above was more extensive, the souffle louder, and it had assumed a see-saw character, masking the sounds of the heart. The patient lingered for some time, and though relieved by treatment, died rather suddenly on May 1 .

Examination after Death.-Our account of the appearances must be confined to the state of the heart and great vessels. The heart was about twice its natural size; its parietes of the natural thickness; the dilatation being equal in all the cavities. The right auricle, excepting the dilatation and hypertrophy, perfectly normal ; the tricuspid valves healthy. The auriculo-ventricular opening is dilated, so as to render the valves somewhat ineffective. In the right ventricle the columne carnex are thicker than normal; the orifice of communication with the pulmonary artery is much dilated. Immediately below the opening is a communication with the left ventricle, which measures about onc-third of an inch across, and oneeighth from above downwards. The two anterior semilunar valves are perfect, of the normal size, but much thickened; the posterior one imperfect, being so narrow and constricted in its middle portion as to be a mere band-like projection from the artery. The pulmonary artery is much dilated, being five inches and three-quarters in its greatest circumference (internal measure); the branches of the pulmonary artery are much dilated. The left auricle is healthy, save the dilatation and hypertrophy; the auriculoventricular opening is dilated; the mitral valve is normal in structure, but not sufficient to close the dilated opening perfectly. In the left ventricle the columnx carnex are thicker than usual, and at the base of the cavity is scen the opening of communication with the right ventricle. 'The opening of the aorta is rather dilated; semilunar valves healthy. The ascending aorta is dilated about one-half beyond its normal size. The distribution of the arteries from its arch may be considered more as divisions of the artery than branches. After giving off these it is contracted to about one-third of its capacity in the ascending portion, and the walls of the vessel are thinned in this situation. This contraction extends from the root of the left subclavian to the joining with the ductus arteriosus, where the artery is still further contracted by a hardened thickening of the conts, projecting into its interior, so as to contract the capacity again to about one-third : so that at this point the capacity of the artery is not more than oneninth of its ascending portion. Just on the distal side of the constriction is the communication with the ductus arteriosus, and immediately below it the artery is dilated to the usual size of the descending aorta.

The second case was one of cyanosis ; the subject of it a young man, aged twenty-one. He had great dyspnœa, palpitations, anasarca, and a blue state of the skin generally. The heat of the body in the axilla, or mouth, was not more than $80^{\circ}$ of Fahrenheit; the state of puberty was not developed. The impulse of the heart was greater than normal; there was a bruit de souffe beginning with the first sound of the heart, sufficiently long to mask the second; it was heard most distinctly under the middle bone of the sternum.

Examination after Death.-The heart and large veins enormously distended with dark-coloured blood; the organ much enlarged and hypertrophied. The septum of the auricles so totally absent as to convert the auricles into one; the veins of the general circulation enter it on the right side of a line drawn in the situation of where the septum should be. The auriculo-ventricular openings are large, and between them the septum of the ventricles is much notched out. The orifice of the aorta is contracted to a third of its usual capacity, and its semilunar valves are diseased and ineffective. The tiver much congested and enlarged, about a third more than its usual size.

\section{ACADEMY OF MEDICINE, PARIS.}

$$
\text { May } 31 .
$$

INJECTION OF VESSELS.

M. Poisseuille read a memoir on a new injection syringe, the pressure produced by which is constant and known.

The advantages arising from the use of this syringe are, according to the author, first, that it shows the normal dimcusions of the vessels that are injected. secorid, that it does not lead to the risk of rupturing the vessels - an accident which so often occurs with the common syringe. The force employed can be made to correspond exactly with that exercised by the heart in the living body.

LATERAL DISTORTION OF THE SPINE.

M. Bouvier presented the spine of a man twentythree years of age ; on this were seen, first, a lateral curvature, existing chiefly between the last dorsal and first lumbar vertebræ; second, a second curvature, occupying the middle of the dorsal region, with the convexity to the right side; third, two other curvatures, placed above the latter, and occupying the superior portion of the vertebral column. There was no projection whatever of the spine backwards, and the man had been passed as a recruit.

A long discussion took place between the author and $\mathbf{M}$. Guerin on the influence of muscular contraction in the production of deviations of the spine. 